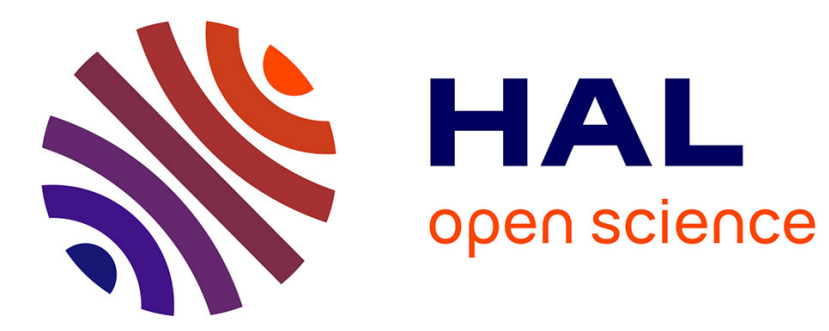

\title{
Stress sensitivity of stylolite morphology
}

\author{
M. Ebner, D. Koehn, R. Toussaint, François Renard, J. Schmittbuhl
}

\section{To cite this version:}

M. Ebner, D. Koehn, R. Toussaint, François Renard, J. Schmittbuhl. Stress sensitivity of stylolite morphology. Earth and Planetary Science Letters, 2009, 277 (3-4), pp.394-398. 10.1016/j.epsl.2008.11.001 . insu-00352914

\section{HAL Id: insu-00352914 https://hal-insu.archives-ouvertes.fr/insu-00352914}

Submitted on 31 Oct 2019

HAL is a multi-disciplinary open access archive for the deposit and dissemination of scientific research documents, whether they are published or not. The documents may come from teaching and research institutions in France or abroad, or from public or private research centers.
L'archive ouverte pluridisciplinaire HAL, est destinée au dépôt et à la diffusion de documents scientifiques de niveau recherche, publiés ou non, émanant des établissements d'enseignement et de recherche français ou étrangers, des laboratoires publics ou privés. 
Ebner, M., Koebn, D., Toussaint, R., Renard, F. \& Schmittbubl, J. 2009. Stress sensitivity of stylolite morphology. Earth and Planetary Science Letters 277(3-4), 394-398.

Postprint, author version.

\title{
Stress sensitivity of stylolite morphology
}

\begin{abstract}
Stylolites are rough surfaces that form by localized stress-induced dissolution. Using a set of limestone rock samples collected at different depths from a vertical section in Cirque de Navacelles (France), we study the influence of the lithostatic stress on the stylolites morphology on the basis of a recent morphogenesis model. We measured the roughness of a series of bedding-parallel stylolites and show that their morphology exhibits a scaling invariance with two self-affine scaling regimes separated by a crossover-length $(L)$ at the millimeter scale consistent with previous studies. The importance of the present contribution is to estimate the stylolite formation stress $\sigma$ from the sample position in the stratigraphic series and compare it to the crossover-length $L$ using the expected relationship: $L \sim \sigma^{-2}$. We obtained a successful prediction of the crossover behavior and reasonable absolute stress magnitude estimates using relevant parameters: depth of stylolite formation between 300 to $600 \mathrm{~m}$ with corresponding normal stress in the range of 10-18 MPa. Accordingly, the stylolite morphology contains a signature of the stress field during formation and we thus suggest that stylolites could be used as paleostress gauges of deformation processes in the upper crust.
\end{abstract}

\section{Introduction}

Stylolites are rough paired surfaces (as illustrated in Fig. 1 A), mainly observed in monomineralic sedimentary rocks. The fact that stylolites can be found in a variety of rocks and display a wide range of morphologies, even within a single outcrop, makes comparison and description of natural stylolites a difficult task (Park and Schot, 1968). Early classifications were mainly based on qualitative parameters such as the visual appearance of the interface and the orientation with respect to the bedding (Park and Schot, 1968; Guzzetta, 1984). Moreover, the necessary overburden for the formation of bedding-parallel stylolites is still debated: up to $800-1000$ m (e.g. Railsback, 1993) whereas other studies (Tada and Siever, 1989 and references cited therein) report depths as shallow as $90 \mathrm{~m}$ for the onset of stylolitization. Stylolites form by localized stress induced dissolution (e.g. Stockdale, 1922; Dunnington, 1954; Rutter, 1983). They reflect important diagenetic processes like local mass transfer, compaction, and porosity reduction in sedimentary basins (e.g. Tada and Siever, 1989). They are often used to estimate the amount 
of dissolved material in the rock (Tada and Siever, 1989), and therefore the total amount of deformation. The long axis of stylolite teeth-like patterns (Fig. 1) is also commonly used to decipher the largest principal compressive stress direction based on field observations (Petit and Mattauer, 1995; Ebner and Grasemann, 2006).

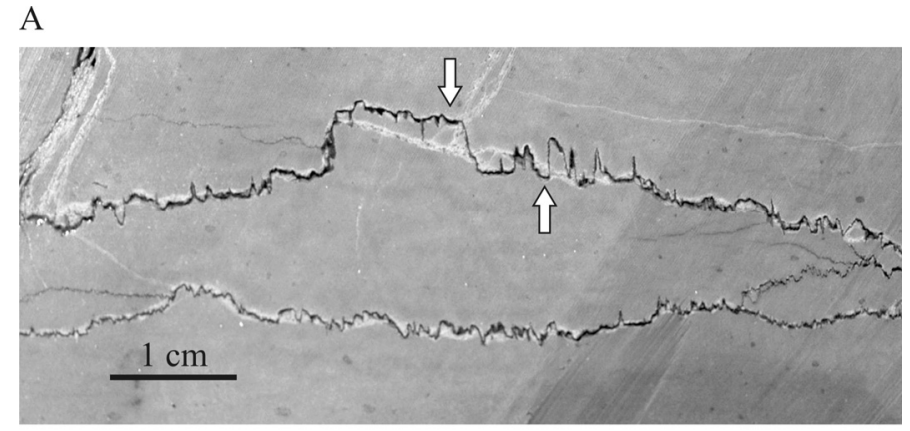

B

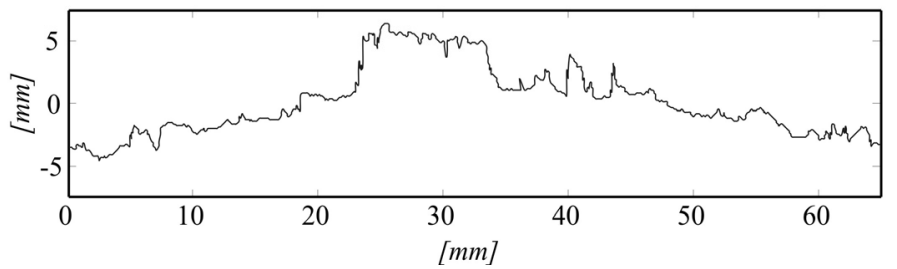

Figure 1 Bedding-parallel stylolite from Cirque de Navacelles (southern France). (A) Plane section of a sample is cut perpendicular to the mean stylolitic plane. Arrow indicates "teeth-like" structures that are oriented parallel to the principal stress direction. (B) 1D roughness of the stylolite shown in A after removal of overhangs and linear trend. This data was used to calculate the scaling properties of the roughness.

Modeling of stylolite morphogenesis is a challenging task (Gal et al., 1998). When their shape is analyzed at large scales and reduced to a flat penny-shape disk, they have been thought to propagate as anticracks (Fletcher and Pollard, 1981). A significant step in stylolite morphogenesis modeling has been obtained from extended roughness measurements in particular 3D profiling of open stylolites. These data have allowed quantitative approaches based on fractal analysis tools (Drummond and Sexton, 1998) and demonstrated fractal scaling invariance over several orders of magnitude of stylolite roughness (Renard et al., 2004; Schmittbuhl et al., 2004; Gratier et al., 2005; Karcz and Scholz; 2003; Brouste et al., 2007). In addition Schmittbuhl et al. (2004) and Renard et al. (2004) observed the existence of a crossover-length (L) that separates two scaling regimes with different roughness exponents for small and large scales. These scaling regimes are consistent with an interface morphogenesis model (Schmittbuhl et al., 2004; Renard et al, 2004) that describes the growth of a stylolite surface as a competition between two stabilizing forces: long range elastic fluctuations and local surface tension, and a destabilizing force due to the presence of heterogeneities in the material. These heterogeneities are thought to be caused by mineral impurities that induce local fluctuations of the elastic moduli. According to this model, the roughening destabilization is induced by the heterogeneities in the material, whereas surface tension balances the roughening process on small and elastic energies on large scales. The key point in the modeling is the prediction of the crossover-length L, i.e. a property of the present stylolite geometry, as a function of the stress field during 
stylolite formation, i.e. the driving paleo-stress. A numerical check of this modeling was proposed by Koehn et al. (2007), which verified the basic assumptions of interrelation between stress orientation and the orientation of stylolite teeth. The motivation of the present work is to examine the link between stylolite morphology and stress magnitude, based on a data set of natural stylolites for which the stress magnitude can be estimated.

\section{Stylolite data-set, roughness measurements and analysis}

We studied a set of 14 bedding-parallel stylolites from Cirque de Navacelles (southern France), where a $300 \mathrm{~m}$ section of flat-lying upper Jurassic limestone crops out (e.g. Bodou, 1976). The investigated succession is an external shelf deposit of the Vocontian Basin that consists mainly of fine-grained (5-40 $\mu \mathrm{m})$ mudstones and wackestones. The top $100 \mathrm{~m}$ is made up of massive Kimmeridgian limestones, whereas the lower $200 \mathrm{~m}$ part contains well-bedded Oxfordian mudstones with higher marl content and a slight secondary dolomitization (Bodou, 1976). The main tectonic overprint in this area is caused by Eocene roughly N-S directed compression from the Pyrenean (e.g. Rispoli, 1981; Petit and Mattauer, 1995). This tectonic phase reactivated subvertical fractures, which trend NE-SW and show a left-lateral displacement. The main tectonic structures are exposed south of the sampling area, but a set of approximately E-W striking vertical stylolites that accompany this tectonic event can be found in the investigated area (Petit and Mattauer, 1995). Such vertical tectonic stylolites were not used or investigated in this study.

The investigated samples were all collected along fresh road-cuts. Only closed interfaces were considered for sampling to avoid overprint due to weathering. In addition, we collected only macroscopically visible stylolites in calcitic limestones for the present study. The samples are very finegrained mudstones and, for all samples, the porosity is secondary and amounts to less than $10 \%$, in line with high seismic velocities measured (see later). Microstructural investigation of the samples showed that bioclast content is below 5-10\% and that clasts do not pin the surface, i.e. do not register in the roughness. The bedding parallel stylolites did not initiate along preexisting planes of anisotropy, such as bedding planes, but originated along sites of stress concentration (e.g. clay particles). Microstylolites observed in thin-section frequently revealed tapered terminations as predicted by the anticrack theory (Fletcher and Pollard, 1981). Insoluble materials, including fine-grained clay minerals that have accumulated along the stylolitic interface do not exceed $0.5 \mathrm{~mm}$ in thickness (Bodou, 1976). The samples were collected along the vertical profile to systematically investigate the influence of lithostatic stress on stylolite roughness.

Since mechanical opening along the stylolitic interface was not possible for most of the samples, we could not investigate the stylolite surface morphology with a profiler (e.g. Renard et al., 2004). Therefore we examined 2D slabs that displayed the stylolite seam.

All oriented specimens were cut normal to the main stylolitic plane to contain the principal stress direction. Each slab was imaged with an SLR camera (sample size along the cut surface is 10-30 cm with a 
pixel resolution of $35 \mu \mathrm{m}$ ) without further treatment (see Fig. 1). The signals were extracted from these images using two different methods. In the first method we manually digitized the images using standard drawing software (CorelDraw(C). To check the consistency of our method and to avoid bias from human input we used a second method, for which we used simple image analysis tools. For that purpose, we clipped the appropriate value range (i.e. the stylolite) from the histogram of the grayscale image and converted the clipped part to a binary image. This image contains the trace of the stylolite from which the boundary pixels were extracted for further treatment.

The raw 1-D profiles (Fig. 1 B) were pre-treated by removing the overhangs to get single valued functions down to the inverse of the Nyquist-frequency (i.e. of twice the pixel size of the digital images). This binning of the raw data was executed using an algorithm that extracts the topmost pixel of the stylolite signal along each vertical column of the image. A reference frame has been defined for each profile, by adjusting its horizontal ( $\mathrm{x}$ ) axis to the global linear trend i.e. a regression over the profile, and the vertical ( $\mathrm{z}$ ) axis is set to have zero mean height. We verified that the signal derived from our stylolite cross-sections shows a scaling behavior similar to extended measurements from 3D topographies by taking side pictures of "opened" stylolites not used in this study, applying the same image extraction technique as described above and comparing the outcome to profiler measurements as suggested by Schmittbuhl et al., (2004).

Results from Schmittbuhl et al. (2004) and Renard et al. (2004) show that stylolite roughness exhibits complex self-affine scaling invariance. A self-affine rough surface is characterized statistically by the fact that points along the surface separated by a distance $\Delta x$ from each other are typically distant in the direction transverse to the surface by $\Delta h \approx \Delta x^{H}$, where $H$ is the roughness or Hurst exponent. Indeed two self-affine regimes are observed on stylolites which can be summed up for the average description of the height difference $\mathrm{h}$ of points along the surface separated by a distance $\Delta x$ as:

$$
h(\Delta x) \approx A \Delta x^{H_{S}} g(\Delta x / L) \quad \text { with } \quad g(u)=\left\{\begin{array}{c}
u^{0} \text { if } u<<1 \\
u^{H_{L}-H_{S}} \quad \text { if } u>>1
\end{array}\right.
$$

where $A$ is a scaling factor $\mathrm{g}$ is a scaling function and $\mathrm{u}$ is the ratio $\Delta x / L$ with $L$ being a crossover-length. $H_{S}, H_{L}$ correspond to the roughness exponents for small and large scales, respectively.

We calculated the Fourier power spectrum $P$ of the stylolite profiles as a function of the wave number k (Renard et al., 2004; Schmittbuhl et al., 2004) (see Fig. 2 A). The power spectrum actually exhibits two power law regimes separated by a crossover at a wave number $k_{L} \approx 1 \mathrm{~mm}^{-1}$. Knowing that the power spectrum of a self-affine profile behaves as: $P(k) \sim k^{-1-2 H}$, we can estimate both roughness exponents from the asymptotic behaviors at small and large scales. To verify our results, we used a second independent signal processing technique, the average wavelet coefficient method (AWC), with Daubechies D4 wavelets (Simonsen et al., 1998). The wavelet spectrum of a self-affine function behaves as a power law with an exponent equal to $1 / 2+H$ (see Fig. 2 B). Using both methods, our results confirm the presence of two scaling regimes with $H_{S} \sim 1.1$ and $H_{L} \sim 0.5$ for small and large length scales respectively. 
A

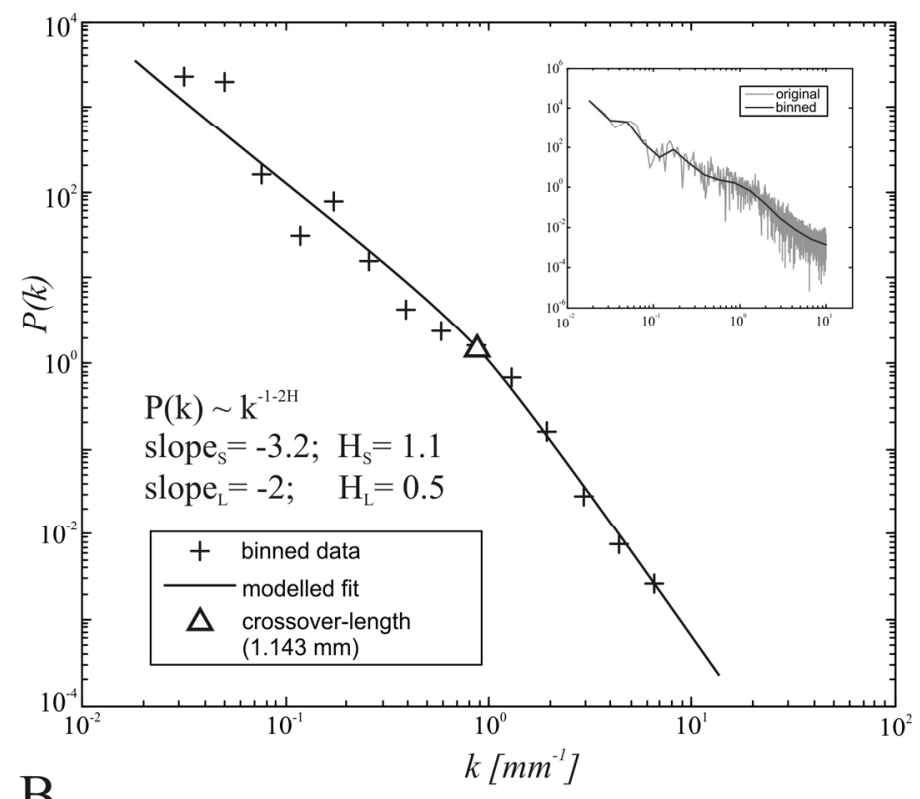

B

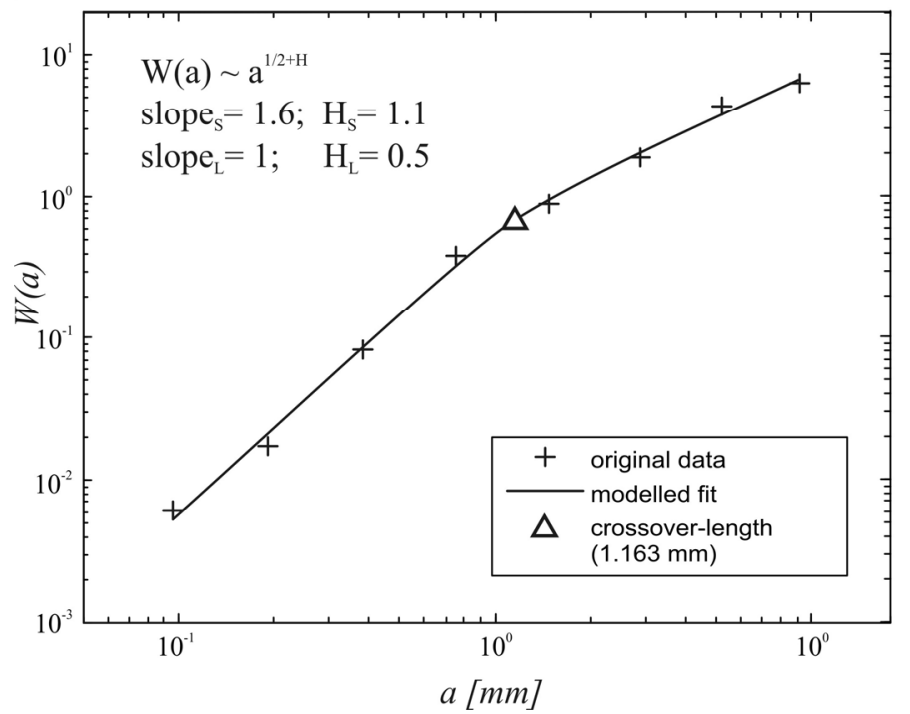

Figure 2 Scaling of Fourier power and averaged wavelet spectra from 1D stylolite profiles. (A) Fourier power spectrum (inset) of the stylolite shown in (A) and logarithmically binned spectrum (crosses) used for nonlinear least square fitting (solid line) with $\mathrm{L}$ indicated by a triangle; $\mathrm{H}_{\mathrm{S}}$ and $\mathrm{H}_{\mathrm{L}}$ denote the roughness exponents of the signal. (B) Averaged wavelet spectrum (AWC) of the stylolite (crosses) of (A) with modeled fit (solid line) and L (triangle). Both independent methods reveal similar values for the crossover-length and roughness exponents of individual samples.

A sensitive task is to estimate precisely the crossover-length scale L. For this, we assumed a linear-byparts fit of the Fourier or wavelet spectra in the logarithmic space, with a crossover function to change from the small scale branch of the scaling law to the large scale one: More precisely, noting in Fourier space, $x=\ln (k)$ and $f(x)=\ln [P(k)]$ with $P(k)$ the power spectrum, or alternatively in wavelet space, $\mathrm{x}=\ln (\mathrm{a})$ where a is the scale parameter, and $f(x)=\ln [W(a)]$ with $W(a)$ the associated average wavelet coefficient, we fit these spectra to the following model: 


$$
f(x)=\left(a_{L} x+m_{L}\right)(1-w(x))+\left(a_{S} x+m_{S}\right) w(x) \quad \text { and } \quad w(x)=\frac{(\tanh (x+L)+1)}{2}
$$

where $a_{L, S}$ are the exponents of the scaling function for large and small scales (i.e. $a_{L, S}=-1-2 H_{L, S}$ in Fourier, and $a_{\mathrm{L}, S}=0.5+H_{\mathrm{L}, S}$ for the wavelet spectrum), $\mathrm{m}_{\mathrm{L}, \mathrm{S}}$ are the corresponding intercepts with the ordinate and $w(x)$ is the weighting function. We fixed the roughness exponents and searched using a least square algorithm the best estimates of $L$ and $m_{L, s}$. In addition we verified that the obtained parameters did not vary along the interface by performing the scaling analysis over independent parts of the same 1D signal. This procedure allowed a robust investigation of the data. Note that to model the data with an equal importance for the large and small scale, we resample the power spectra with a logarithmic binning, i.e. to get a constant density of data points over the complete spectrum in logarithmic representation.

\section{Results}

We calculated the crossover-lengths $L$ for all samples from Fourier and wavelet spectra. Figure $3 \mathrm{~A}$ shows the correlation between $L$ and the relative vertical position of the sample in the stratigraphic series. We observe that $L$ decreases from $\sim 2.1 \mathrm{~mm}$ near the top (525 Meters Above Sea level - MAS) to $\sim 0.7$ $\mathrm{mm}$ at the bottom of the series (250m - MAS), which corresponds to a factor 3 for almost $300 \mathrm{~m}$ of relative depth. The crossover-length for sample N2 is clearly off the trend (see Fig. 3 A) for both methods but the respective roughness exponents are similar compared to the other samples (Fig. $3 \mathrm{~B}$ ). A way to check the consistency of our crossover length-scale estimate is to collapse all data on a single curve (i. e. a uniform scaling function) using $L$ to scale the horizontal distance along the sample and the vertical magnitude of the roughness for all samples (see Fig. 3 B for the collapse of the wavelet spectra) as proposed by Renard et al. (2004). The accordance of the collapse is a measurement for the quality of the overall fit of L for all samples. Indeed, a good data collapse should demonstrate that the crossover-lengths used to normalize the data are correct for individual samples. We however notice a systematic offset of $\sim 0.13 \mathrm{~mm}$ between estimates of $L$ from the Fourier spectra and that from the wavelet spectra. This systematic offset is of the same order of magnitude as the precision of measurement of $L$ as indicated in Fig. 3 A. Error analysis performed by Schmittbuhl et al. (1995) revealed that the Fourier analysis is more sensitive to signal length and self affinity of the signal compared to the AWC analysis (Simonsen et al., 1998) when using synthetic signals with known properties. Hence in the following we correct the Fourier estimates by adding this offset to all the values.

Schmittbuhl et al. (2004) and Renard et al. (2004) established from first principles of mechanics and thermodynamics a model for stylolite growth under the form of a stochastic partial differential equation (a generalized Langevin equation), which successfully described stylolite growth as a competition between material disorder and stabilizing forces such as surface tension and elastic interactions. 

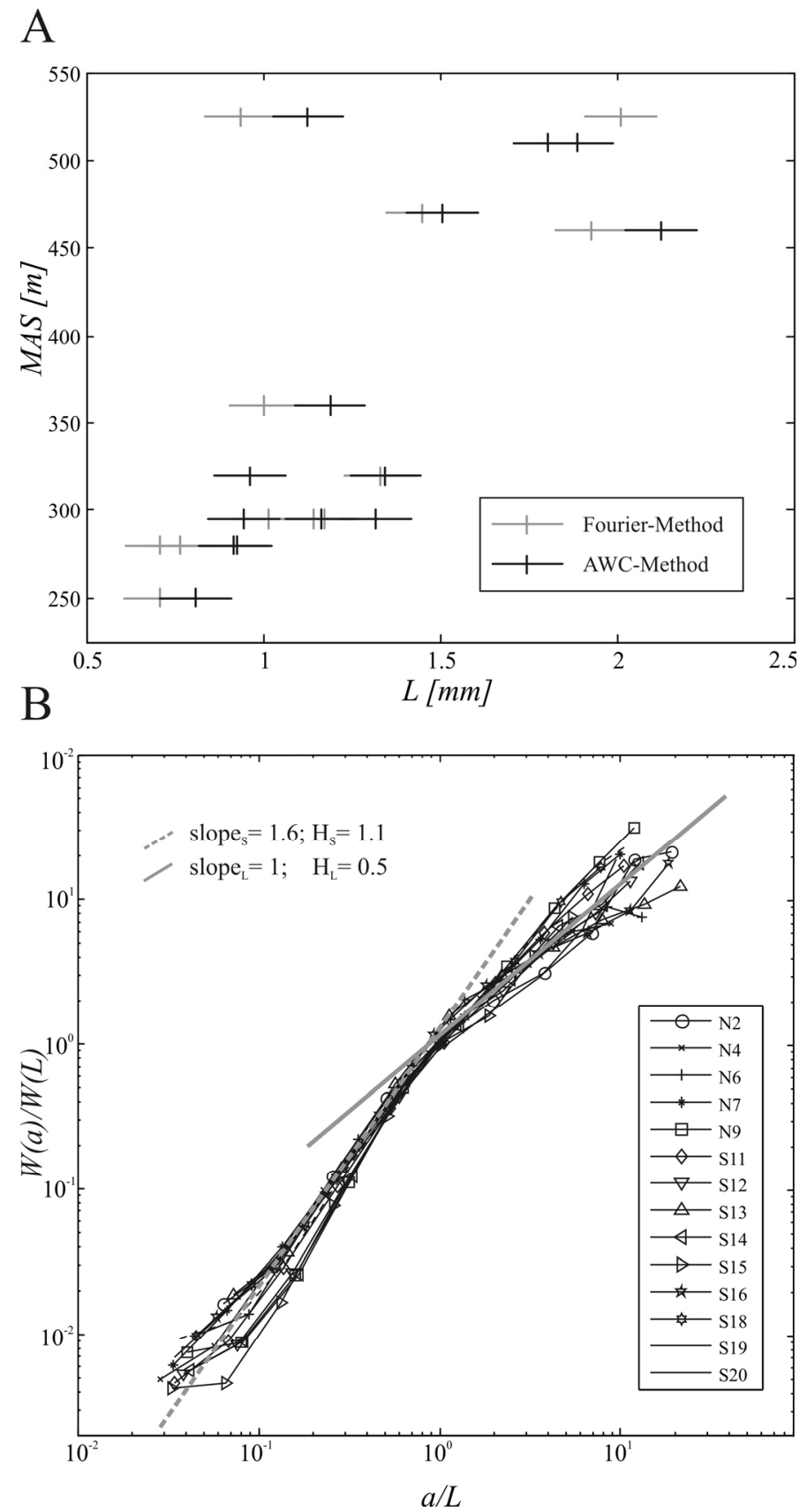

Figure 3 Crossover-length and scaling data for all samples. (A) Relative sample position MAS (=meters above sea-level) versus $\mathrm{L}$ for the whole stylolite data set (error-bars indicate the precision of measurements). Notice the increase in $\mathrm{L}$ with the sample vertical position in the profile. (B) Data collapse for the scaling functions of all samples for the AWC method. L is used to normalize the scaling functions demonstrating that there is one scaling function common to all stylolites investigated.

Hence a possible link between $L$, surface tension and the state of stress during stylolite formation has been proposed by Schmittbuhl et al. (2004):

$$
L=\frac{\gamma E}{\beta \sigma_{m} \sigma_{d}}
$$

where $E$ is the Young's Modulus, $\gamma$ is the solid-fluid interfacial energy, $\beta=v(1-2 v) / \pi$ is a dimensionless constant with $v$ the Poisson's ratio, $\sigma_{m}$ and $\sigma_{d}$, are the mean and differential stresses respectively. For the 
Cirque de Navacelles stylolites, we assumed that the main principal stress is vertical $\left(\sigma_{z_{2}}\right)$, whereas both horizontal stresses are equal and smaller than the vertical stress component. Accordingly, $\sigma_{m}=1 / 3\left(\sigma_{\text {ra }}+\right.$ $\left.2 \sigma_{x x}\right)$ and $\sigma_{d}=\sigma_{\text {站 }}-\sigma_{x x}$. Finally, we consider the strain to be uniaxial (i.e. zero horizontal displacement), which is a reasonable simplification for the early stages of sedimentation in most basins. This allowed us to relate the horizontal and vertical components of stress $\left(\sigma_{x x}=\sigma_{y y}=[v /(1-v)] \sigma_{z z}\right)$. Expressing the mean and differential stresses as a function of the vertical principal normal stress $\left(\sigma_{z z}\right)$ gives: $\sigma_{m} \sigma_{d}=a \sigma_{z z}{ }^{2}$ with $a=$ $1 / 3[(1+v) /(1-v)][(1-2 v) / 1-v)]$. Introducing these estimates in Equation 3 provides a relationship between the crossover $L$, the surface tension and the principal normal stress component $\sigma_{z:}$ :

$$
L=\frac{\gamma E}{\beta} \cdot \frac{1}{\alpha \sigma_{z z}^{2}}
$$

if the physical parameters are known. For the surface free energy, we adopted a typical value of a calcitewater interface in limestones, $\gamma=0.23 \mathrm{~J} / \mathrm{m}^{2}$ (Wright et al., 2001). We assumed a Poisson's ratio $\nu=$ $0.25 \pm 0.05$ (Clark, 1966).

The last step is to measure the vertical stress independently of Equation 4. This is obtained assuming that the vertical stress equals the weight of overburden, i.e. lithostatic stress: $\sigma_{\text {z }}=\varrho g$ z with $\varrho$ is the rock-density; $g$ is the acceleration of gravity $\left(9.81 \mathrm{~m} / \mathrm{s}^{2}\right)$, and $z$ the depth. We measured a constant bulk density from our samples of: $\varrho=2.7 \mathrm{~g} / \mathrm{cm}^{3}$.

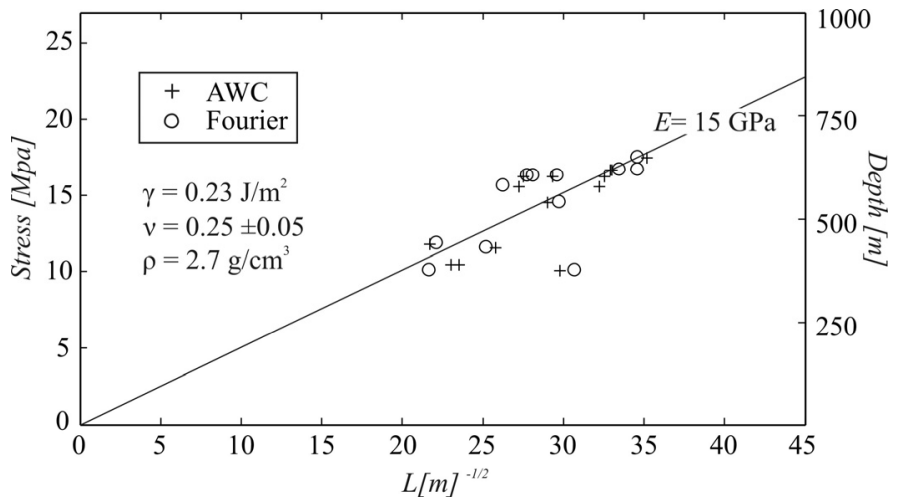

Figure 4 Plot of a principal normal stress as a function of $\mathrm{L}^{-1 / 2}$. The plot illustrates the linear dependence of the field data and demonstrates that a linear trend for both scaling-methods confirms the analytical solution of Schmittbuhl et al., (2004). The slope of the linear fit of the natural datasets (solid line) correspond to a Young's modulus of $15 \mathrm{GPa}$ for a given set of material properties $(\varrho, \gamma, \nu)$ calculated from Eq. 4.

We rearranged Equation 4 in a way that stress is plotted as a function of $L^{-1 / 2}$ in order to obtain a linear relationship (Fig. 4). That this plot exhibits such a linear behavior demonstrates the consistency of our model. The plot shown in Figure 4 suggests that the roughness of bedding-parallel stylolites contains a significant signature of the stress-field during formation of the stylolites. We found that the Young's modulus was $\mathrm{E}=15 \mathrm{GPa}$, i.e. the regression line through the data points, which is in line with values measured on limestones (Clark, 1966). Our dataset indicates that the thickness of the overlying rock mass was $\sim 300 \mathrm{~m}$ (which can be read from the representation in Figure 4), which corresponds to $\sim 10 \mathrm{MPa}$ 
and $\sim 18 \mathrm{MPa}$ of vertical normal stress at the top and bottom of the investigated section, respectively, applying the stated assumptions. The related horizontal normal stresses were then $\sim 4 \mathrm{MPa}$ and $\sim 6.5 \mathrm{MPa}$.

\section{Discussion \& Conclusions}

To characterize the present material constants, we determined the elastic parameters for two characteristic rock samples using seismic wave velocity measurements under laboratory conditions. From the $\mathrm{P}$ and S-wave velocities we calculated the elastic parameters (Jaeger et al., 2007) of two representative samples (ST-17: $E=86 \mathrm{GPa}, v=0.09 ; \mathrm{N}-6: E=97 \mathrm{GPa}, \nu=0.05)$. The elastic parameters are clearly different from the values plotted in Figure 4. Indeed, during stylolite formation, the rock was softer and the Young's modulus and Poisson's ratio might have been different than for a compacted rock. Given that carbonates are prone to diagenetic alterations that may modify the porosity and thus seismic velocities, especially in the vicinity of a stylolite (Raynaud and Carrio-Schaffhauser, 1992), the elastic parameters derived from our samples may be strongly altered (Anselmetti and Eberli, 1993). Accordingly mechanicochemical tests to reproduce the observed stylolites using present rock samples would be inappropriate.

Equation 4 shows that the crossover length is a function of the elastic properties, which are strongly influenced by the rock porosity (e.g. Eberli et al., 2003). It is likely that the elastic parameters evolve with the compaction process, consequently the elastic parameters may change with depth. We do not think that our observed trend in the stylolite crossover is a function of varying elastic parameters. In order to explain such a smooth variation of the crossover over the whole profile by a variation of one of the parameters (Young's modulus, porosity or density) would require that these parameters vary smoothly and linearly with depth, which is not very often the case (compare Eberli et al., 2003). For example a decrease in porosity down-section, i.e. an increase in the Young's modulus, would result in a non-linear increase of the crossover-length with depth. This seems to be a second order effect since our data are consistent with a linear relationship (Eq. 4) and more importantly a decrease of L with depth.

Our assumption that elastic parameters are constant throughout the profile implies that the kinetics of the roughening must be fast relative to the progressive burial of rocks so that the stylolite roughness can re-equilibrate with depth. Schmittbuhl et al. (2004) demonstrated that the time to saturate the roughness and thus develop self-affine scaling invariance and a respective crossover-length is in the order of 200 years. Even high accumulation rates in platform carbonates usually do not exceed $\sim 40 \mathrm{~m} / \mathrm{my}$ i.e. less than $1 \mathrm{~cm}$ in 200 years (e.g. McNeill, 2005), which would easily allow the re-equilibration of the roughness. Under the assumption that the timescale for the roughening would be much larger than that for a change in the accumulation of the burial load, stylolites would record the terminal stresses before they become inactive. We conclude that our constant Young's modulus assumption seems to fit the data over the investigated range but further investigations are necessary that span greater differences in formation depth. It has to be added that the measured vertical distances between the samples in the section were probably larger during formation of the stylolites due to ongoing compaction of the rock- 
mass. This effect would result in a telescoping of the data along the ordinate of Figure $3 \mathrm{~A}$ and an opposite effect would be noticed in Figure 4, i.e. the slope through the data would be steeper.

Another assumption used in this study is that all stylolites formed more or less simultaneously, which is indeed questionable. However, if the stylolites formed one after the other when their host rock reached a certain depth in the basin, they would not reveal a difference in crossover-lengths.

It can be further noticed that another petrographical factor, the transition from massif to bedded mudstone layers, does not register in the observed crossovers. We are therefore confident that these large scale heterogeneities played, if any, a negligible role in the scaling of the crossover-length in the investigated section. Additional analysis is necessary to investigate the influence of different lithologies from the same structural level since we only investigated very homogeneous mudstone along the section. In summary we suggest that the systematic variation of the crossover-length in the investigated section is mainly a function of stress. Our results are in line with differential stress/depth relations obtained from in-situ stress measurements and comparable to other paleo-piezometers e.g. calcite twinning (Lacombe, 2007 and references cited therein).

We propose that bedding-parallel stylolites can be considered as quantitative stress gauges because their roughness depicts the stress field during formation. Investigation of a set of samples from different depth allows determining their depth of formation and the absolute stress magnitudes if the assumptions stated above can be adopted.

In this contribution we investigated bedding-parallel stylolites that formed due to lithostatic overburden. This setting allows simplifications that are not valid for stylolites that formed in response to a stress field that has its largest principal stress direction oblique to the Earth's surface. Assessment of the stress field around vertical stylolites needs more prerequisites e.g. a test if the scaling is isotropic as in the case of bedding-parallel stylolites and, further, needs good depth constraints e.g. from independent methods or under favorable circumstances from horizontal stylolites with the method proposed here. Knowledge of these quantities would enable us to investigate stresses around vertical stylolites and thus magnitudes of tectonic loading in the Earth's crust.

\section{References}

Anselmetti, F.S., Eberli, G.P., 1993. Controls on Sonic Velocity in Carbonates. Pure Appl. Geophys. 141 (2-4), 287-323.

Bodou, P., 1976. Importance of the stylolitic joints in the compaction of limestones. Bull. Centre Rech. Pau - SNPA 10, 627-644.

Brouste, A., Renard, F., Gratier, J.P., Schmittbuhl, J., 2007. Variety of stylolites' morphologies and statistical characterization of the amount of heterogeneities in the rock. J. Struct. Geol. 29 (3), 422434.

Clark, S.P.J., 1966. Handbook of Physical Constants. Geological Society of New York, New York.

Drummond, C.N., Sexton, D.N., 1998. Fractal structure of stylolites. J. Sediment. Res. 68 (1), 8-10. 
Dunnington, H.V., 1954. Stylolite development post-dates rock induration. J. Sediment. Petrol. 24 (1), 2749.

Eberli, G.P., Baechle, G.T., Anselmetti, F.S., Incze, M.L., 2003. Factors controlling elastic properties in carbonate sediments and rocks. The Leading Edge 22, 654-660.

Ebner, M., Grasemann, B., 2006. Divergent and convergent non-isochoric deformation. J. Struct. Geol. 28 (10), 1725-1733.

Fletcher, R.C., Pollard D.D., 1981. Anticrack model for pressure solution surfaces. Geology 9 (9), 419424.

Gal, D., Nur, A., Aharonov, E., 1998. Stability analysis of a pressuresolution surface. Geophys. Res. Lett. 25 (8), 1237- 1240.

Gratier, J.P., Muquet, L., Hassani, R., Renard, F., 2005. Experimental microstylolites in quartz and modeled application to natural stylolitic structures. J. Struct. Geol. 27 (1), 89-100.

Guzzetta, G. 1984. Kinematics of Stylolite Formation and Physics of the Pressure-Solution Process. Tectonophysics 101, 383-394.

Jaeger, J.C., Cook, N.G.W., Zimmermann, R.W., 2007. Fundamentals of rock mechanics. Blackwell Publishing Ltd, Oxford.

Karcz, Z., Scholz, C.H., 2003. The fractal geometry of some stylolites from the Calcare Massiccio Formation, Italy. J. Struct. Geol. (8), 1301-1316.

Koehn, D., Renard, F., Toussaint, R., Passchier, C.W., 2007. Growth of stylolite teeth patterns depending on normal stress and finite compaction. Earth Planet. Sc. Lett. 257 (3-4), 582-595.

Lacombe, O., 2007. Comparison of paleostress magnitudes from calcite twins with contemporary stress magnitudes and frictional sliding criteria in the continental crust: Mechanical implications. J. Struct. Geol. 29 (1), 86-99.

McNeill, D.F., 2005. Accumulation rates from well-dated late Neogene carbonate platforms and margins. Sediment. Geol. 175 (1-4) 73-87.

Park, W.C., Schot, E.H., 1968. Stylolites: their nature and origin. J. Sediment. Petrol. 38 (1), 175-191.

Petit, J.P., Mattauer M., 1995. Palaeostress superimposition deduced from mesoscale structures in limestone: the Matelles exposure, Languedoc, France. J. Struct. Geol. 17 (2), 245-256.

Railsback, L.B., 1993. Lithologic Controls on Morphology of Pressure-Dissolution Surfaces (Stylolites and Dissolution Seams) in Paleozoic Carbonate Rocks from the Mideastern United-States. J. Sediment. Petrol. 63 (3), 513-522.

Raynaud, S., Carrio-Schaffhauser, E., 1992. Rock matrix structures in a zone influenced by a stylolite. J. Struct. Geol. 14 (8-9), 973-980.

Renard, F., Schmittbuhl, J., Gratier, J.P., Meakin, P., Merino, E., 2004. Three-dimensional roughness of stylolites in limestones. J. Geophys. Res.-Sol. Ea. 109 (B03209), doi:10.1029/2003JB002555.

Rispoli, R., 1981. Stress fields about strike-slip faults inferred from stylolites and tension gashes. Tectonophysics 75, 29-36. 
Rutter, E.H., 1983. Pressure solution in nature, theory and experiment. J. Geol. Soc. London. 140 (5), 725740.

Schmittbuhl, J., Vilotte, J.P., Roux, S., 1995. Reliability of Self-Affine Measurements. Phys. Rev. E 58 (1), 131-147.

Schmittbuhl, J., Renard, F., Gratier, J.P., Toussaint, R., 2004. Roughness of stylolites: Implications of 3D high resolution topography measurements. Phys. Rev. Lett. 93 (238501), doi:10.1103/ PhysRevLett.93.238501.

Simonsen, I., Hansen, A., Nes, O.M., 1998. Determination of the Hurst exponent by use of wavelet transforms. Phys. Rev. E 58 (3), 2779-2787.

Stockdale, P.B., 1922. Stylolites: their nature and origin. Indiana University Studies 9, 1-97.

Tada, R., Siever, R., 1989. Pressure Solution during Diagenesis. Annual Review of Earth and Planetary Sciences 17, 89-118.

Wright, K., Cygan, R.T., Slater B., 2001. Structure of the (10(1)over-bar4) surfaces of calcite, dolomite and magnesite under wet and dry conditions. Phys. Chem. Chem. Phys. 3 (5), 839-844. 